\title{
TRÊS OBJEÇõES DE ALASDAIR MACINTYRE APLICADAS AO DEBATE MULTICULTURAL
}

\author{
Willian Martini ${ }^{1}$ \\ Universidade Federal de Santa Catarina (UFSC) \\ (iD) https://orcid.org/0000-0002-2577-8543 \\ E-mail: willianmartini@hotmail.com
}

\section{RESUMO:}

Segundo Alasdair MacIntyre, existem três características problemáticas que perpassam grande parte das contendas morais e políticas contemporâneas e às quais não se têm dado atenção suficiente: a) existe uma incomensurabilidade conceitual dos argumentos adversários nos debates travados; b) as argumentações em curso se fazem passar por argumentações racionais impessoais; c) as premissas conceitualmente distintas dos argumentos usados têm uma grande diversidade de origens históricas. A partir dessas três colocações e das consequências delas advindas, vamos aplicar o raciocínio crítico de MacIntyre a um conjunto específico de argumentos em conflito no terreno do multiculturalismo. Nosso intuito com isso é explorar as diferentes concepções e princípios que estão na base das posições vistas e também realizar um pequeno balanço acerca da justificação comunitarista para um modelo político multicultural.

PALAVRAS-CHAVE: Multiculturalismo; Moralidade; Comunitarismo; Liberalismo.

\section{THREE OBJECTIONS FROM ALASDAIR MACINTYRE APPLIED TO THE MULTICULTURAL DEBATE}

\begin{abstract}
:
According to Alasdair MacIntyre, there are three problems that pervade most contemporary political struggles and which have not been given sufficient attention: a) there is a conceptual incommensurability of the adverse arguments in the debates; b) the ongoing arguments represent impersonal rational arguments; c) the conceptually distinct premises of the used arguments have a great diversity of historical origins. From these three settings and their consequences, we will apply MacIntyre's critical reasoning to a specific set of conflicting arguments in the field of multiculturalism. Our aim is to explore the different conceptions and principles that underlie the positions seen and also to make a balance on the communitarian justification for a multicultural political model.
\end{abstract}

KEYWORDS: Multiculturalism; Morality; Communitarianism; Liberalism.

\footnotetext{
1 Doutorando em Filosofia na Universidade Federal de Santa Catarina (UFSC), Florianópolis - SC, Brasil. Bolsista Capes.

MARTINI, Willian. Três objeções de Alasdair MacIntyre aplicadas ao debate multicultural. Griot : Revista de Filosofia, Amargosa - BA, v.18, n.2, p.217-232, dezembro, 2018. 


\section{MacIntyre e o debate moral contemporâneo}

Em seu livro After Virtue, publicado em 1981, Alasdair MacIntyre tem como objetivo central restaurar a ética de virtudes e assim superar muitos dos principais problemas que afetam o debate moral contemporâneo. Segundo nos diz o próprio MacIntyre, "a tese principal de Depois da Virtude é que a tradição moral aristotélica é o melhor exemplo que possuímos de uma tradição cujos adeptos têm racionalmente o direito a uma dose maior de confiança em seus recursos epistemológico e moral". (MACINTYRE, 2001, p. 465). De modo geral, o livro argumenta em prol da ideia de que a inteligibilidade mútua dos agentes morais depende, em larga medida, da comunidade e da tradição nas quais eles estão inseridos. Para dar sustentação a essa tese, uma monumental e complexa obra é produzida (são buscados recursos tanto sociológicos quanto históricos) sendo que uma das tarefas indispensáveis para esta empreitada é a construção de uma crítica à influência da filosofia moral moderna sobre a índole das nossas atuais discussões.

Nossa pretensão aqui não é apresentar em pormenores as ideias centrais de Depois da Virtude (2001), mas queremos nos concentrar sobre algumas das críticas particulares feitas por MacIntyre aos parâmetros de racionalidade que são priorizados na análise de questões morais, o que por vezes acarreta em um acentuado ceticismo relativamente aos elementos históricos e culturais e às suas potenciais contribuições para os debates filosóficos. Dessa maneira, é sobretudo o capítulo 2 da obra de MacIntyre que nos interessa, mais especificamente, a marcante característica da reflexão moral contemporânea de manifestar-se através de discordâncias que culminam em debates intermináveis. ${ }^{2}$ Esta insolubilidade dos pontos de vista acerca da moral tem uma correspondência filosófica com o emotivismo e com o existencialismo, e também com uma visão instrumental da realidade social humana, a partir da qual as pessoas não seriam tomadas enquanto fins, mas como meros agentes operando funções no sistema burocrático. ${ }^{3}$ Embora nossa preocupação inicial seja o "interminável" debate moral, outros pontos relevantes serão vistos com referência a este primeiro nível. Afinal, na medida em que buscamos evidenciar os traços gerais do pensamento comunitarista, vemos que tanto Charles Taylor quanto MacIntyre tratam de rejeitar alguns dos grandes movimentos da filosofa moral do início do século XX por motivos semelhantes. ${ }^{4}$

Ao abrir o segundo capítulo de sua obra, MacIntyre nos apresenta três grupos de argumentos que supostamente constituiriam bons exemplos acerca de temas correntes em discussão não apenas nas academias, mas também no noticiário e no dia-a-dia. O primeiro grupo de argumentos é sobre o pacifismo, o segundo sobre a questão do aborto e o terceiro sobre critérios de justiça. Embora todos os argumentos sejam muito interessantes, pois realçam de maneira mais clara os princípios

\footnotetext{
${ }^{2}$ Capítulo 2: A natureza da atual discordância moral e as afirmações do emotivismo. In MACINTYRE, 2001, p. $21-49$.

3 Tugendhat aponta que a tese de MacIntyre acerca da falta de um programa moral unitário é desenvolvida em três níveis: o primeiro, do qual nos ocuparemos, trata da nossa incapacidade de resolver as questões morais de modo racional; o segundo nível, trata de sua rejeição do emotivismo; e o terceiro versa sobre a instrumentalização do agir humano. (TUGENDHAT, 1996, p. 210).

${ }^{4}$ A esse respeito, ver TAYLOR, A Ética da Autenticidade, 2011, mais precisamente, o seu delineamento daquilo que julga ser o subjetivismo das motivações como fundamento para a ação, no capítulo 6, p. 63 -76.
} 
envolvidos em cada alegação, a título de exemplo será suficiente citarmos apenas aqueles pertencentes ao segundo grupo sobre a temática do aborto:

(1) Todos têm certos direitos sobre a sua pessoa, entre eles sobre o próprio corpo. Segue-se que, da natureza desses direitos, no estágio em que o embrião faz parte do corpo da mãe, ela tem o direito de tomar sua própria decisão espontânea acerca de querer ou não interromper a gravidez. Por conseguinte, o aborto é permissível e deve ser permitido.

(2) Não posso desejar que minha mãe tivesse abortado quando estava grávida de mim, a não ser, talvez, se houvesse certeza de que o embrião estivesse morto (...). Mas, se não posso desejá-lo em meu próprio caso, como posso negar a outros o direito à vida que reivindico para mim mesmo? Eu transgrediria a Regra de Ouro, a menos que negasse que a mãe tem, em geral, direito ao abortamento. Não defendo, portanto, a opinião de que o aborto devia ser proibido por lei.

(3) Assassinar é errado. Assassinar é tirar a vida de um inocente. O embrião é um indivíduo identificável, cuja única diferença do recémnascido é estar num estágio anterior rumo às capacidades adultas e, se é que há vida inocente, a desse embrião o é. Se infanticídio é assassinato, como realmente é, o abortamento é assassinato. Por conseguinte, abortar não é apenas moralmente errado, mas devia ser proibido por lei. (MACINTYRE, 2001, p. 22-23.).

Aparentemente, estamos diante de um conflito intelectual comum, com argumentos estruturados a partir de diferentes perspectivas sobre um mesmo assunto. A contenda seria passível de alguma solução racional, como qualquer questão moral o poderia ser. A ideia defendida por MacIntyre, entretanto, é a de que cada argumentador funda-se sobre um conceito que restringe a plausibilidade da disputa ao seu próprio ponto de vista. Desse modo, o objeto em dada questão será entendido e avaliado através de sua própria versão dos fatos, do entendimento propiciado pelos princípios morais vigentes em cada argumento. Segundo MacIntyre, são três as características que têm perpassado as contendas morais e políticas contemporâneas e que têm impossibilitado a resolução dos debates morais: (a) a existência de uma incomensurabilidade conceitual dos argumentos adversários no debate; (b) essas argumentações se fazem passar por argumentações racionais impessoais; (c) as premissas conceitualmente distintas da argumentação têm uma grande diversidade de origens históricas. Veremos brevemente como cada um desses pontos é compreendido por MacIntyre.

A característica apontada em (a) remete ao infrutífero embate entre premissas igualmente aceitáveis. Os argumentos que defendem ou condenam a legitimidade moral e legal do aborto, por exemplo, são logicamente válidos ou podem tornar-se válidos com um melhor arranjo da forma como estão estruturados, ou seja, a conclusão parece realmente derivar das premissas. Todavia, as premissas usadas em cada caso são tais que não temos como compará-las diretamente, porque "cada premissa emprega um conceito normativo ou avaliativo diferente das outras, de modo que as afirmações são de tipos bem distintos" (Ibidem, p. 24). Nos argumentos (1) e (3), premissas sobre os direitos se opõem às premissas em (2) que se apoiam na possibilidade da universalização. Ora, como vamos decidir racionalmente qual modelo de análise e avaliação tem mais peso (moralmente falando) na nossa compreensão dos fatos? Um jurista conservador, outro liberal e um filósofo kantiano 
discordariam substancialmente acerca dos aspectos mais relevantes para se decidir algo em torno do aborto. Seriam discordâncias mais profundas e a princípio insolúveis, já que cada qual possuiria as suas próprias razões.

Em (b) procura-se problematizar a maneira como as razões apresentadas estão desprendidas dos agentes envolvidos e das circunstâncias reais da elocução moral. Para uma melhor explanação deste ponto, distingue-se entre expressões de preferência pessoal, nas quais a força justificadora depende de quem as emite e para quem; e expressões normativas, cuja força justificadora não depende do contexto e do sujeito da elocução. Para ilustrar isso, MacIntyre sugere um cenário em que dois agentes se engajam em uma conversa: A diz para B "faça tal coisa", ao passo que B responde "por que devo fazer isso?" Se a resposta de A for algo do tipo "porque quero", não se oferece motivo ou razão alguma para o pedido inicial de A. No entanto, no caso de estarmos num contexto de subordinação militar, no qual A é um oficial e B um soldado, ou no caso de serem A e B um casal apaixonado numa conversa provocativa, a resposta "porque quero" indica realmente ao interlocutor um motivo, embora não suficiente. Entretanto, se A diz algo como "porque é seu dever" ou "porque agradaria a um maior número de pessoas", parece que temos motivações racionalmente aceitáveis, independentemente de quem as enuncia e para quem. A consequência disso é que "o elo especial entre o contexto da elocução e a força justificativa, que sempre se mantém no caso de expressões de preferência ou desejo pessoal, se rompe no caso de elocuções morais" (Ibidem, p. 26). Podemos perceber que questões circunstanciais em torno do aborto (quem está grávida? Como aconteceu? Quais são as condições sociais e econômicas para se criar um filho? O pai sumiu? Os parentes próximos desaprovam? etc.) não são acolhidas pela abordagem filosófica, a qual pretende contribuir para uma decisão no plano legal por meio de juízos morais universais para os quais fatores contingentes são irrelevantes, são acidentes casuais que não tocam os princípios morais usados.

O que está em questão em (c) é a contingência histórica dos conceitos envolvidos. $O$ autor afirma que "os argumentos acima comparam um conceito de direito de antecedentes lockeanos com a possibilidade de universalização kantiana, e há ainda um apelo ao direito moral que é tomista" (Ibidem, p. 28). Pretende-se chamar a atenção para o fato de que os autores que nos legaram os conceitos já desenvolvidos e que usamos correntemente viveram em épocas diferentes e dentro de culturas e sociedades diferentes. Tendemos a esquecer os fatos que envolvem a complexa atuação dos contextos históricos sobre o desenvolvimento do significado de um termo moral relevante. No delineamento desta terceira característica, é muito provável que MacIntyre esteja se servindo - e desenvolvendo sua própria reflexão a partir daí - do clássico artigo de Elizabeth Anscombe que trata exatamente das mudanças históricas que subverteram os sentidos que termos como "obrigação" e "dever" mantiveram no seio de sua tradição original. ${ }^{5}$

\footnotetext{
${ }^{5}$ Enquanto MacIntyre tenta restabelecer alguns traços fundamentais da ética grega (como a noção teleológica de Bem) em sua proposta para resolver a confusão conceitual no debate moral contemporâneo, Anscombe vislumbra uma saída mais radical, mas apenas assim que dispusermos de explicações fundamentadas por uma adequada filosofia da psicologia: "The concepts of obligation, and duty - moral obligation and moral duty, that is to say and what is morally right or wrong, and of the moral sense of "ought", ought to be jettisoned if this is psycologically possible". (ANSCOMBE, G.E.M., 1958, p. 1) Também podemos encontrar mais sobre o desenvolvimento e o impacto da filosofia de Anscombe em SATTLER, J. 2012, p.103 - 144. Algumas críticas
} 
Estas três características engendram objeções gerais sobre a índole das nossas atuais discussões sobre filosofia moral. Tugendhat notou, com razão, que não podemos extrair uma conclusão forte acerca de todos os debates morais com base em apenas algumas amostras particulares de casos que apresentam argumentos contrários sobre um mesmo tema. (Cf. TUGENDHAT, E. 1996, p. 211). Não obstante, somos levados a admitir que a abordagem de MacIntyre, mesmo não podendo dar esse passo lógico, provoca uma alteração significativa em nossa percepção a respeito de alguns dos elementos subentendidos neste quadro argumentativo. Certas noções de base sobre o que é uma disputa racional estão arraigadas de tal maneira em nosso pensamento, que suas problemáticas consequências muitas vezes nos passam despercebidas.

Buscando agora destacar aspectos de outra ordem nos debates morais, vamos deslocar a abordagem crítica de MacIntyre para o campo do multiculturalismo. Testaremos a hipótese segundo a qual nossas contendas nunca chegarão a uma conclusão sólida devido à falta de uma unidade básica para os estudos morais feitos pelos modernos e seus herdeiros. Nesse sentido, nosso próximo passo é apresentar as discordâncias entre algumas das principais correntes do multiculturalismo na filosofia política, para, em seguida, aí aplicarmos o raciocínio crítico de MacIntyre. O objetivo desta análise crítica é uma melhor compreensão da estrutura argumentativa em pauta para a temática multicultural e o vislumbre de uma possível dissolução de seus pontos em disputa.

\section{O debate do multiculturalismo e a crítica de Brian Barry}

Ao perscrutar os argumentos inerentes à discussão envolvendo o convívio de diferentes grupos étnicos e culturais em um mesmo território nacional, percebemos que também aqui os filósofos engajados nessa discussão nos apresentam bases distintas para suas alegações no debate multicultural: por exemplo, Will Kymlicka (1995) apoia-se sobre os princípios do liberalismo para fundamentar as decisões políticas e sociais relativas aos diferentes grupos de problemas envolvendo imigrantes, nativos ou minorias nacionais; Charles Taylor (1994) constrói seu discurso sobre a questão da formação da identidade pessoal e da identidade de grupo através do reconhecimento advindo dos "outros importantes"; outros autores falam ainda em reparação histórica devido às injustiças cometidas no passado e às marcas do colonialismo que ainda encontram-se visíveis em nossa sociedade (IVISON, D., 2006). Podemos perceber que o elemento justificador contido em cada abordagem possui um aporte teórico diferente, no sentido de que apela a uma diferente instância de consideração a fim de dar sustentação à exigência feita. Dentro da filosofia política, esses diferentes vieses teóricos operam com uma finalidade comum, qual seja, a de justificar a demanda geral do multiculturalismo por leis e direitos que observem as reivindicações feitas com base nas especificidades culturais e religiosas dos grupos minoritários.

interessantes às formulações de Anscombe são feitas em CRISP, R. 2006. Na terceira parte do nosso artigo, vamos entrar no texto Modern Moral Philosophy, de Anscombe, para uma breve discussão. 
De outro ponto de vista, Brian Barry critica a noção de justiça que acredita estar na base de sustentação dos argumentos em prol do multiculturalismo. Ele resume a forte reivindicação multicultural da seguinte maneira: "It is said, the same law, may have a different impact on different people as a result of their religious beliefs or cultural practices. Thus, the liberal claim that equal treatment is generated by a system of uniform laws is invalid". (BARRY, 2001, p. 34). Mas Barry não está disposto a aceitar este argumento, e responde dizendo que as minorias religiosas e culturais deveriam ser consideradas responsáveis pelas consequências decorrentes de suas próprias crenças e práticas. Afirmando que afiliações religiosas e culturais são muito diferentes de uma deficiência física, ele argumenta que as primeiras não restringem as pessoas da maneira como as deficiências físicas o fazem. Uma deficiência física comporta uma forte reivindicação prima facie de compensação porque ela limita as oportunidades de uma pessoa para engajar-se em atividades nas quais os outros são capazes de fazê-lo (Cf. SONG, S. 2016).

A pretensão de nosso trabalho é aplicar as críticas de MacIntyre ao debate que se configura entre a argumentação exposta acima e as possíveis justificações para o multiculturalismo. Embora os autores aqui analisados articulem discursos filosoficamente complexos e com recursos derivados de diversas fontes, vamos sintetizar o essencial da posição sustentada por cada um deles para obtermos argumentos mais apreensíveis, semelhantes aos que encontramos em torno da questão do aborto acima. Assim, o igualitarismo de Barry pode ser mais ou menos caracterizado como se segue:

(1) O papel de uma lei justa é apenas assegurar uma gama de oportunidades iguais e não assegurar a possibilidade de acesso igual a quaisquer escolhas ou resultados particulares. Uma vez que as reivindicações culturais e religiosas estão assentadas somente sobre as disposições dos indivíduos pertencentes às minorias e não sobre uma dificuldade (fisicamente) intransponível, tais reivindicações devem ser abandonadas.

A posição multicultural sustentada por Charles Taylor também pode ter o seu argumento sumariamente resumido com base em sua perspectiva do reconhecimento:

(2) O não reconhecimento ou o reconhecimento incorreto por parte dos "outros" pode acarretar o desenvolvimento de uma identidade distorcida e malograda, sendo que as pessoas podem "adotar uma opinião depreciativa a respeito de si próprias"(TAYLOR, 1994, p.46). O respeito não é apenas um ato de gentileza, mas uma necessidade humana vital, de modo que, se a única maneira de preservar as práticas culturais e religiosas dentro das quais os sujeitos conseguem se reconhecer (e formar uma identidade sadia) é através de concessões e leis especiais para grupos minoritários, então tais concessões devem ser atendidas.

Will Kymlicka adapta os princípios de igualdade e de autonomia às exigências gerais do multiculturalismo, buscando assim preservar o núcleo teórico do liberalismo para a sua justificação de uma política multicultural: ${ }^{6}$ ${ }^{6}$ Assim como outras versões liberais do multiculturalismo, o desenvolvimento da proposta de Kymlicka surge,
em boa medida, como uma reação aos fortes ataques comunitaristas à suposta neutralidade dos princípios de 
(3) A cultura possui inestimável valor instrumental para os indivíduos porque ela fornece uma gama adequada de opções a partir das quais se pode escolher, o que é fundamental para o exercício da autonomia. Portanto, uma vez que os membros dos grupos minoritários se encontram em desvantagem em termos de acesso aos itens da própria cultura (ao contrário dos membros da cultura dominante), temos de conceder direitos especiais para minorias culturais a fim de sanar essas desigualdades.

Como dito acima, as razões que cada um dos autores tem para suas afirmações são sobremodo mais sofisticadas e complexas do que isso. O que nos interessa, entretanto, é que uma síntese de argumentos deste gênero parece ser um bom modelo para a comparação de ajuizamentos sobre um objeto comum, aceito por nossa filosofia moral quase como um paradigma metodológico: uma mistura de supervalorização dos critérios formais de análise junto a um desprezo (muitas vezes inconsciente) pelos elementos históricos e interpretativos que penetram a discussão através dos conceitos envolvidos. No entanto, o pensamento comunitarista volta-se para os nossos conceitos basilares e suas origens dentro de contextos e tradições diferentes, ao passo que rejeita o critério de neutralidade típico de nossas "elocuções morais". MacIntyre não teria que observar cada uma das disputas de nossos atuais debates para inferir algo acerca de todos eles, porque aquilo que lhe interessa é atacar o padrão normativo de racionalidade que é imposto de cima, não interceptando e estruturando, mas suprimindo as reivindicações normativas pertencentes, de maneira mais íntima, ao conteúdo do que é afirmado num argumento. Mas tal raciocínio procede? É o que tentaremos responder na próxima seção.

\section{Multiculturalismo e incomensurabilidade: um diálogo de surdos?}

Em que medida o conflito entre os argumentos acima reproduz os mesmos tipos de caso que os apontados por MacIntyre? As razões apresentadas estão de fato afastadas das situações reais de fala dos sujeitos, a ponto de não se referirem a contextos e sujeitos factuais, mas meramente idealizados? As raízes históricas dos conceitos relevantes para o debate multicultural tornam a discussão confusa ou fragmentada? O debate aqui apresentado está concentrado sobre a questão política envolvendo os grupos culturais, étnicos e as minorias religiosas, mas as reivindicações neste plano, da mesma maneira que os argumentos sobre o aborto, estão apoiadas em bases morais filosóficas, o que nos coloca, portanto, diante do mesmo gênero de debate que o apresentado por MacIntyre.

Assim, qual é o ponto de apoio básico das premissas em questão? Apesar dos argumentos de Barry e Kymlicka atingirem conclusões opostas, ambos pretendem sustentar suas premissas sobre o conceito de igualdade. Mas, enquanto Barry pensa que este conceito deve estar ligado apenas ao campo de oportunidades disponíveis

justiça (que ganhou força com Rawls nos anos 1970) e à concepção atomista do indivíduo, (noção moderna que pressupõe, entre outras coisas, uma sociedade na qual as pessoas não possuem fortes vínculos entre si). Mais sobre esta discussão pode ser encontrado em: LOIS, C. C. Justiça e Democracia: entre o Universalismo e o Comunitarismo, 2005. 
aos indivíduos, Kymlicka os liga às garantias de acesso à cultura. Partindo do mesmo ponto, eles constroem diferentes entendimentos para o sentido de "igualdade" que deve ser preservado no interior de uma teoria liberal igualitária. Kymlicka afirma que sem estar seguro de poder usufruir dos aspectos fundamentais de seu próprio grupo cultural, fica difícil preservar a autonomia plena do indivíduo, já que haveria aí certa restrição relativamente ao seu campo de escolhas. Barry, no entanto, não pensa que grupos sejam entidades às quais se possam conceder direitos especiais, pois, ao ir além da concessão de iguais recursos e oportunidades, o Estado estaria também envolvido com alguma concepção substantiva de "bem" - já que parece haver um forçoso incentivo por parte das políticas multicultuais para que pessoas livres e independentes reconheçam seus valores básicos em uma identidade coletiva sobreposta às características que elas podem escolher desenvolver como indivíduos. E sobre isso um Estado liberal justo deve manter-se neutro.

Para Kymlicka, a proposta de direitos específicos para grupos não é oposta aos direitos individuais, mas é um passo que visa assegurar a vigência dos princípios liberais num cenário global de nações heterogeneamente formadas, com diferentes tipos de grupos minoritários. Kymlicka afirma que a liberdade, em geral, "finds its basis in the autonomy of a national group" (KYMLICKA, 1955, p.7). A autonomia não é concedida somente aos indivíduos tomados em relação a um Estado democrático hegemônico, mas tem que atender também às demandas das formações comunitárias no interior de uma grande nação. Autogoverno para grupos indígenas é um exemplo. No entanto, a fim de se preservar a integridade universalizante de seus princípios, haveria ainda a possibilidade de intervenção legal em casos extremos, o que garantiria a centralidade dos ideais liberais sobre às concessões dadas pelos Estados democráticos aos diferentes tipos de grupos. Ao integrar uma minoria religiosa, por exemplo, alguém pode estar isento de cumprir uma lei de aplicação geral, mas se este mesmo sujeito quiser abandonar as práticas de sua religião e se converter às crenças locais, ele deve ter seus direitos assegurados, mesmo que isto não seja previsto por sua tradição de origem.

A distinção entre o espaço público e o espaço privado não pode mais transcorrer em uma dicotomia simples em Kymlicka, como o era para os liberais clássicos. Isso abre caminho para um modelo político multicultural no qual os grupos surgem como graus distintos de mediação entre estas duas esferas (SEMPRINI, 1999, p.137). Ao rejeitar a base cultural para a concessão de direitos de grupo, Barry joga ainda com a pressuposição da neutralidade absoluta do espaço público, o que restringe as questões referentes às diferenças ao âmbito do privado, dentro dos limites de um corpo de regras igualmente estabelecido para todos os cidadãos. Embora Kymlicka fuja das restrições de um modelo cívico homogeneizador para pensar a diversidade cultural da sociedade contemporânea, ele "considera que uma reivindicação multicultural não pode tomar forma senão em relação a uma maioria monocultural, detentora do controle do aparelho judiciário no quadro de um estado de direito" (SEMPRINI, 1999, p. 138). Este posicionamento em relação ao papel do Estado no multiculturalsmo também é uma das fontes de tensão entre as abordagens de Kymlicka e Taylor, embora Taylor reconheça que o tipo de reivindicação de uma 
política multicultural tenha seus antecedentes no desenvolvimento moderno da noção de igual dignidade. ${ }^{7}$

Na medida em que o igualitarismo está voltado para a equidade de direitos entre indivíduos e esquece a dimensão cultural e simbólica da formação da identidade, como o faz Barry, a política da diferença lhe é alheia, mas talvez isso não denote uma incongruência, e sim apenas um atrito mais superficial entre às posições liberais envolvidas no debate. Agora, quando Taylor usa o conceito de reconhecimento como sustentáculo de premissas pela sobrevivência das práticas culturais, é possível notar uma incongruência em relação aos conceitos básicos dos liberais e dos igualitários. Em Taylor, os bens que podem ser perseguidos pelos integrantes de um grupo minoritário só existem porque é sua própria cultura que fornece um horizonte moral a partir do qual certos itens aparecem como desejáveis ou dignos de serem buscados. Aquilo que um indivíduo escolhe para si é coletivamente construído como valoroso no interior de certas práticas (religião, arte, diálogos, etc.), sem as quais não é possível que humanos se reconheçam como pessoas com certas características particulares. Tal noção, na força empregada por Taylor, admite que a cultura tenha valor em si, podendo ser priorizada, por exemplo, relativamente aos direitos dos indivíduos pertencentes às maiorias nacionais. ${ }^{8}$

A política de diferença defendida pela variante liberal de Kymlicka não garante por tempo indefinido as condições para a prosperidade das práticas dos grupos, uma vez que procura cobrir apenas as vantagens de acesso para os membros das minorias, sem permitir que o imperativo da sobrevivência de uma tradição apareça na forma de limitação de direitos dos indivíduos pertencentes aos grupos culturais hegemônicos. Apesar da adaptação de algumas reivindicações importantes do comunitarismo para a sua teoria, Kymlicka diferencia-se de Taylor de uma maneira mais profunda, já que o caráter instrumental da cultura em relação ao indivíduo denota a centralidade não dos aspectos constitutivos da identidade dos sujeitos, mas do exercício de direitos dentro de um quadro teórico liberal. Barry, por sua vez, opõe-se ao próprio conteúdo do conceito de igualdade sugerido pela teoria liberal do multiculturalismo, e seu modo de apreciar os problemas envolvidos não concede nenhum espaço para a noção de reconhecimento do comunitarismo.

Ora, se a característica apontada em (a) por MacIntyre for aplicável aqui, então os conceitos que servem de base aos argumentos estruturados também estabelecem o seu próprio padrão normativo. Ou seja, cada qual faz a sua própria avaliação dos fatos em torno dos quais gira a possibilidade de uma política multicultural de ser aplicada. Igualdade e autonomia de um lado e o reconhecimento do outro. São conceitos que nos dão perspectivas variadas sobre como pensar adequadamente um mesmo problema.

Mas seriam eles incomensuráveis? Quando pensamos o reconhecimento no âmbito da representatividade das identidades coletivas, remetemos à categoria da diferença pensada essencialmente em seu vínculo com as relações intersubjetivas e a

${ }^{7}$ Este ponto poderia fornecer uma coerência de fundo ao debate, invalidando assim nossa pretensão de aplicar as colocações de MacIntyre aos argumentos do multiculturalismo. Mas as diferentes concepções sobre grupo e indivíduo, bem como dos propósitos de um estado democrático nessas questões prevalecem, revelando diferentes núcleos antropológicos das posições multiculturais adversárias.

${ }^{8}$ Este é o caso, por exemplo, dos anglo-descendentes serem proibidos de falar inglês em algumas regiões do Québec. TAYLOR, 1994, p. 75. 
necessidade do respeito entre grupos. Enquanto a igualdade, na maior parte dos casos, "mesmo quando estendida a todo o corpo social, refere-se apenas aos direitos formais, administrativos e legais do indivíduo" (SEMPRINI, 1999, p. 93), desconsiderando todas as dissimetrias culturais encontradas em uma sociedade heterogeneamente formada. O embate entre a "igualdade" dos liberais e o conceito de diferença do multiculturalismo produz, segundo Semprini, uma aporia conceitual (portanto, uma disputa sem perspectivas de resolução) - declaração que encontra ressonância nas afirmações de MacIntyre.

MacIntyre está consciente de que ao falar de "incomensurabilidade conceitual" ele trata de questões morais usando um vocabulário importado da filosofia da ciência. Na verdade, ele assume uma concepção mais "ortodoxa" de incomensurabilidade, sem buscar problematizar este controvertido conceito. Para Bezerra (2012), por exemplo, "a tese da incomensurabilidade parece ter uma consequência fortíssima a nível metodológico, a saber, a impossibilidade de fazer-se qualquer comparação entre teorias diferentes, em particular, qualquer comparação dos seus respectivos méritos cognitivos". Mas o raciocínio de MacIntyre adquire consistência quando ligamos a impossibilidade racional de comparação entre os conceitos relevantes com os fatores envolvendo os contextos de suas origens históricas. Isso nos leva ao que foi enunciado em (c) - sendo que vamos deixar o item (b) para tratarmos por último.

\section{História e conceito: reconhecimento e comunidade em Taylor}

Temos de entender que, para MacIntyre, um contexto é sempre engendrado por um ethos específico (tomado como um conjunto de crenças, hábitos, práticas comuns pertencentes a uma comunidade ou nação), e é dentro dele que um esquema conceitual e uma linguagem moral adquirem significado. Uma teoria que se pense possuidora das normas universais para a avaliação das ações humanas independentemente destes contextos particulares fica um pouco aquém do insight comunitarista. Neste ponto, novamente, pensamos que MacIntyre alinha o seu pensamento com Anscombe, e é aí então que se torna relevante falar de "incomensurabilidade" em relação ao percurso temporal dos conceitos importantes para a moral.

O sentido que um termo carrega não pode ser pensado fora dos valores socialmente construídos e dos acidentes históricos em volta dele. $\mathrm{O}$ entendimento de como um termo moral pode ser apresentado em um enunciado depende de fatos fundamentais da cultura que, de certa forma, são anteriores à formação das implicações deste termo. Anscombe nos chama a atenção para o fato de que o termo 'dever', quando aparece em um enunciado moral, contém o sentido de: "você tem a obrigação de", ou "é necessário você agir dessa maneira". O 'dever' nos traz implicações normativas fortes que atuam no constrangimento da ação do indivíduo frente às circunstâncias apresentadas por seu meio social. Ela argumenta que os termos correntes 'dever' ou 'tem de' aderiram a um sentido especial (moral) que os equipou com a ideia de "exigência", de compromisso relativo a uma lei. É um sentido que implica certa necessidade, algo que pode ser exigido por lei. Estes termos adquiriram tal sentido e força nos modos de falar e de pensar os fenômenos morais 
graças ao cristianismo. Segundo Anscombe, pode-se notar isso na transformação sofrida pela palavra ó $\mu \alpha \rho \tau \alpha ́ v \varepsilon ı v$, que em grego significa algo como "errar o alvo", "não acertar", e que com o cristianismo, através de sua transcrição para a palavra latina pecattum, passou a significar "pecar". No contexto da teologia legalista que o mundo medieval herdou da Torá semita, o pecado repercutia uma falta contra a ordem divina, cujo descumprimento era merecedor de castigo e danação eterna. ${ }^{9}$

A questão à qual Anscombe nos leva gira em torno dos sentidos historicamente localizados dos termos-chave em uma discussão. Quando esta autora sugere que a perda do vínculo entre um conceito moral e o contexto de sua origem implica a perda do suporte necessário para a inteligibilidade correta de tal conceito, nos perguntamos de que maneira podemos então manter o uso de tais conceitos? As palavras ainda exercem sua força relativa à certa regulação do social, porém, somos levados a conjecturar novos meios de sustentação para a imputação de seu conteúdo normativo. Dessa maneira, o projeto da filosofia moderna de justificar a moralidade foi, em parte, a tentativa de fundamentar a exigência prática sobre uma estrutura epistemológica provedora do caráter necessário e universal pertencentes apenas à natureza abstrata do próprio conceito (e que outrora pertencia a Deus). Mas quais mudanças ocorreram com o advento da modernidade e quais são relevantes para a nossa discussão? Em Taylor, o conceito de reconhecimento e a relevância da realidade interna de um grupo cultural emergem em seus estudos através do seu contato com Hegel.

Hegel busca apresentar a comunidade como uma instância total da qual os indivíduos participam enquanto membros. Esta concepção se desvia da visão da sociedade como formada por um contrato baseado no direito natural moderno ou como um instrumento destinado a assegurar a felicidade geral. Quando Hegel toma a comunidade como um organismo do qual os indivíduos são partes constituintes, longe de apresentar uma concepção excêntrica ou mística, ele torna possível pensarmos que este organismo possui o seu modo de ser, uma linguagem interna que lhe é própria, fonte da cultura a partir da qual uma especificidade consciente é construída: "o indivíduo possui sua cultura, e, por conseguinte, sua identidade ao participar dessa vida mais ampla [...] o fato é que nossa experiência é o que é - é, em parte, moldada - pela maneira como a interpretamos" (TAYLOR, 2005, p.113). Nossa maneira de ver o mundo depende dos materiais de que dispomos em nossa cultura e do seu intercâmbio entre os indivíduos.

\footnotetext{
9 Em seu livro de 2006 Reasons and the Good, Roger Crisp afirma que Anscombe está enganada ao acreditar que

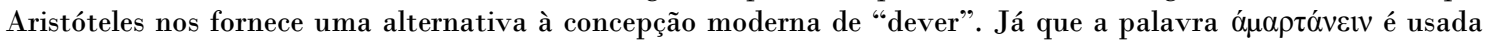
num contexto de discussão moral por Aristóteles, ela pode muito bem significar "errar o alvo moral". Dessa maneira, uma vez que a carência de uma virtude denotada pelas ações de alguém implica em provável reprovação, o caráter do "erro" apontado apresenta um teor impositivo que é semelhante à exigência do cumprimento de uma lei, tanto em sua amplitude como em seu poder de reivindicação. Mas, poderíamos objetar, esta analogia de Crisp entre normatividade moral e legal talvez simplifique um pouco o entendimento sobre como o conteúdo conceitual e a própria linguagem usada se entrelaçam num contexto, pois, não podemos esquecer que o suposto "dever ser virtuoso" aristotélico não depende da aceitação de um preceituário normativo, seja ele divino, legal ou puramente racional (do qual a lei extraí sua força), mas de nossas concepções filosóficas sobre a natureza humana e o modo mais adequado para a realização do télos deste tipo de ser. Muito embora este tipo de resposta pudesse ser dado por MacIntyre e não por Anscombe. Outros pontos importantes de discordância, em especial com relação à etimologia de 'dever', também são discutidos em CRISP, 2006, p. 27- 35.
} 
É devido ao papel constitutivo do social, como uma totalidade da qual emanam as individualidades, que Taylor prioriza a sobrevivência de tradições étnicas e religiosas minoritárias sobre certos direitos individuais que os Estados democráticos julgam absolutos. Existe um choque entre a concepção liberal do indivíduo como entidade ontológica autônoma e independente, tal como pressuposta nos textos de Barry e Kymlicka, por exemplo, e a concepção que vê a formação do todo social como a estrutura ontológica elementar, o universal que, dialeticamente, tem nos particulares a sua atualidade e sua racionalidade. A evocação do papel essencial da comunidade para justificar o constrangimento das liberdades individuais parece uma objeção óbvia ao raciocínio hegeliano. Entretanto, diria Hegel, o que nos leva a ver a liberdade situada no afastamento de nossos vínculos sociais é exatamente a alienação, que retira do nosso campo de visão os valores inerentes ao convívio comunitário.

Mas, neste sentido hegeliano, como viemos a nos tornar alienados? Isto é, como a individualidade tornou-se irresistivelmente tão mais forte do que o sentido de pertencimento a um grupo? As transformações modernas inauguram um cenário com novos objetos de valoração, e o surgimento do indivíduo neutro e desprendido é um aspecto fundamental da concepção ontológica não confessa ligada ao surgimento dos ideais do liberalismo. Ora, esta discussão nos leva justamente ao item (b) levantado por MacIntyre, sobre as argumentações racionais impessoais como critérios para a identificação de uma elocução moral.

\section{Neutralidade e Desprendimento na modernidade: sobre a construção do agente moral}

De que maneira respostas como "agradaria a um maior número de pessoas" ou "você deveria fazer isso", adquiriram a força justificativa que possuem para nós? A fonte de sua força moral seria uma propriedade intrínseca à forma de inteligibilidade racional propiciada por estas sentenças? $O$ importante, tal como sugere o raciocínio de Taylor, não é pensarmos na universalidade do raciocínio moral em si, nas características de seu ser lógico, mas sim nos elementos pressupostos pelo pano de fundo de nossos objetos de valor, nossas noções de bem. Estas podem ser tomadas como articuladoras do nosso "espaço moral": os horizontes ontológicos dentro dos quais uma formulação adquire um sentido moral. ${ }^{10}$

A questão da disponibilidade de diferentes bens nas diversas culturas e a consequente formação de espaços morais heterogêneos pode nos saltar aos olhos como um relativismo intelectualmente fraco. Mas tal objeção só é plausível na medida em que nossas discussões foram historicamente direcionadas por um modelo de racionalidade que suplantou os objetos de valor de outras culturas, em geral, culturas que não possuíam uma linguagem especializada na forma de uma ciência. Na modernidade, nossas noções de bem passaram a ser compatibilizadas com

10 TAYLOR, C. As fontes do self: a construção da identidade moderna, 2005. Ver o capítulo 2: "O self no espaço moral", p. 41 - 77. Nesta perspectiva, um self não teria propriedades morais caso seu horizonte de apreensão não apresentasse pontos de referência, ou seja, certos bens a partir dos quais um sujeito faz suas avaliações, guiando sua vida e conferindo sentido a suas ações. Da mesma forma que requeremos certas noções para nossa orientação espacial também precisamos de objetos de valoração forte (bens) para que nossos comportamentos sejam discernidos como moralmente relevantes, em pelo menos alguns casos. Assim, há uma estreita correlação entre nosso sentido de self e o sentido de bem que subjaz à formação de nossas intuições morais de base.

MARTINI, Willian. Três objeções de Alasdair MacIntyre aplicadas ao debate multicultural. Griot : Revista de Filosofia, Amargosa - BA, v.18, n.2, p.217-232, dezembro, 2018. 
propriedades interiores, tornando a relação do sujeito com sua vida moral, em vários aspectos, como um tipo de cálculo que otimiza a operacionalidade de um sistema. A noção de "razão desprendida" de Descartes e a noção de "sujeito pontual" em Locke, tal como apresentadas por Taylor, nos dão uma ideia do modo pelo qual certa compreensão da propriedade racional do ser humano instrumentalizou a relação agirpensar. Em Descartes, a dicotomia interior/exterior adquire sua força a partir da concepção representacional, a versão da mente como um painel interno que deve ser ordenada de acordo com percepções claras e distintas. Esta nova noção passa a conferir dignidade ao ser pensante a partir de algo inerente a sua condição subjetiva, mas isso, apenas na medida em que a razão tem sua função instrumental (internamente) controladora das paixões e (exteriormente) manipuladora da natureza.

Segundo Taylor, um traço desse importante passo dado por Descartes é o distanciamento que assumimos de nossa própria experiência: ela é negada enquanto entidade fenomenológica, isto é, a experiência não é um meio, mas consiste num objeto. A razão desprendida cartesiana tornou-se um lugar comum no discurso moderno. Locke, por sua vez, articula essa intuição básica à sua noção de consciência, que Taylor chama de self "pontal". Isso possibilita a auto objetificação no plano moral: o self é o centro (estático) de regulação das mudanças em um quadro de objetos postos pela experiência ${ }^{11}$. Epistemicamente falando, o racionalismo e o empirismo descartam a antiga concepção ôntica do logos ordenador e sustentam uma crença mecanicista sobre o reino da natureza.

Nossa hipótese, juntamente com Taylor, é a de que através destes autores podemos ver alguns dos fundamentos para um tipo específico de valoração do indivíduo que se tornou central para a moralidade. Na modernidade o indivíduo não é pensado através dos aspectos variáveis da história que culminaram em sua época e em suas vivências, mas é tomado de um modo acultural, a partir de supostos predicados universais e necessários envoltos às suas disposições cognitivas. ${ }^{12}$ Assim, o agente moral é aquele capaz de exercer sua autonomia exatamente na medida em que seu raciocínio se mostra impessoal. Uma elocução possui conotação moral apenas se apresentar uma justificação de caráter racional (desprendida e neutra) na qual o sujeito é isolado de sua história e do contexto real de seu contato com outros agentes morais. Desse modo, os próprios princípios de igualdade e autonomia, como sustenta Barry ou Kymlicka, por exemplo, não poderiam ser pensados fora da sua emergência tal como aparecem em Locke; ou sem a concepção da dignidade universal do homem com base em seu poder racional, como encontrada em Descartes. Todavia, obviamente estes autores não foram os criadores da individualidade moderna (que é o sustentáculo da tradição liberal na política ocidental), embora os seus trabalhos recriem e articulem filosoficamente tal noção individualista de self.

11 Ibidem, p. 210: "O desprendimento é sempre correlativo a uma objetificação (...). Objetificar determinado domínio envolve privá-lo de sua força normativa para nós. Se tomarmos um domínio do ser no qual até então a forma de ser das coisas estabeleceu as normas ou os padrões para nós, e adotarmos uma nova postura neutra em relação a ele, nós o objetificamos".

12 Cf. Calandín, J. G. Modernidad hermenéutica en Charles Taylor. Quaderns de filosofia i ciència, 40, 2010, pp. 105-114. "Los enfoques descontextualizados de la modernidad, hacen pensar que «lo natural» siempre fueron las sociedades individualistas. Contra esta estrechez de miras el mejor antídoto que se nos presenta es recordar; recuperar La genealogía de nuestra sociedad. En esto radica la importancia del contraste que nos permite distinguir los principales rasgos de la concepción moderna del orden moral" (p. 108).

MARTINI, Willian. Três objeções de Alasdair MacIntyre aplicadas ao debate multicultural. Griot : Revista de Filosofia, Amargosa - BA, v.18, n.2, p.217-232, dezembro, 2018. 


\section{Considerações Finais}

Com tudo o que foi visto até aqui, podemos dizer que a leitura de MacIntyre pode ser parcialmente aplicada aos argumentos do multiculturalismo que apresentamos desde que situemos na base de nossa investigação o método hermenêutico utilizado por alguns dos representantes do comunitarismo. Embora a comunicabilidade entre épocas e autores seja intuitiva e mesmo inegável (nós os lemos e discutimos seus pontos de vista), podemos estar fazendo leituras erradas de teorias filosóficas quando esquecemos quais são realmente seus fundamentos, dado um ethos, as circunstâncias sociais, culturais, econômicas, institucionais e as ideias que acompanharam seu desenvolvimento.

Sobre a incomensurabilidade (a), afirmamos que ela não existe com relação a Barry e Kymlicka. Ambos apelam para premissas sobre a igualdade e a autonomia e, como já visto, embora haja discordâncias fortes, o desacordo remete apenas à extensão adequada destes conceitos para uma teoria liberal e igualitária. Barry quer manter um escopo mais exíguo para aquilo que o igualitarismo abrange, enquanto Kymlicka tenta estender estes conceitos de modo a comportar a situação de pluralismo das sociedades contemporâneas. Enquanto esta contenda é potencialmente passível de resolução (ao menos em princípio), não podemos dizer o mesmo com referência ao reconhecimento de Taylor. Como já vimos, mesmo que uma lei multicultural exista apenas dentro de um Estado democrático de direito, uma concessão de cidadania pode ultrapassar algumas diretrizes que nenhuma teoria liberal, por mais aberta que seja, pode suportar. $O$ foco de Taylor é a relação do sentido de self com determinado meio cultural. Neste sentido, o aparelho democrático de direito é uma circunstância cultural na estruturação da política de vários Estados ocidentais, mas isto não pode implicar a prioridade absoluta deste modelo político sobre outras culturas, porque a tradição formadora das noções de bem subjacente à história do Ocidente lhes é alheia. Não podemos obrigar outras culturas a reconhecer o valor do regime democrático só porque este nos parece absoluto. $O$ reconhecimento implica estar aberto a aceitar que certos aspectos da vida em grupo são bens valiosos para os outros, embora a realização de nossa vontade individual (com base em nossos direitos) pareça ultrapassar infinitamente algumas exigências da vida em comunidade destas outras culturas. Mas a incomensurabilidade parece existir aqui justamente porque, a princípio, não dispomos dos meios que nos tornam inteligível de que maneira certos bens podem vir a ser tomados como tais; e as teorias liberais tendem a não englobar este ponto ao seu espectro conceitual, que é exatamente o que Taylor procura fazer.

Sobre a questão da impessoalidade e racionalidade das elocuções morais (b), apesar do tratamento bastante sucinto a este ponto dado na seção anterior, procuramos demarcar alguns pontos que apresentam como alguns dos principais filósofos modernos foram edificando os traços fundamentais que nos permitiram alcançar uma concepção do discurso moral como descontextualizado, isto é, fortemente enraizado nas propriedades formais do próprio discurso e na natureza necessária e universal da normatividade imposta pelos princípios morais. A justificação moral para o multiculturaismo, na versão liberal, ou para a sua negação, como em Barry, está sempre circunscrito no âmbito dos direitos formais, que consiste 
num corpo preestabelecido de prescrições a ser aplicado a casos particulares, mediante análise cuidadosa. $O$ argumento de Taylor, entretanto, busca a sustentação das reivindicações multiculturais atendendo as peculiaridades e contingências relacionadas possibilidade de sobrevivência das tradições culturais que não compartilham as noções de bem e outras características culturais dos grupos hegemônicos.

Em (c), com as diferentes origens históricas dos conceitos evolvidos, vimos que o reconhecimento em Taylor tem seu foco sobre a concepção de formações comunitárias nas noções encontradas em Hegel, o qual estava inserido num contexto da filosofia alemã que sofria forte influência do romantismo. O movimento romântico procurou resgatar de diversas maneiras aspirações mais antigas que haviam sido perdidas dentro das revoluções operadas no período moderno (em parte, uma totalidade harmonizante estava sendo evocado para responder às fragmentações que afastavam o sentido da vida individual do sentido conferido à "vida" do cosmo). Brian Barry e Will Kylimcka, por outro lado, abraçam a linguagem jurídica e os amplos pressupostos sobre a natureza do indivíduo que foram desenvolvidos na modernidade através de transformações que refletiram sobre as concepções acerca dos direitos universais e a prioridade da igualdade dos indivíduos sobre as diferenças entre formações comunitárias. ${ }^{13}$

O nosso artigo não pretendeu fazer quaisquer juízos de valor com referência às teorias e tradições que foram vistas, mas antes, procurou especular a existência de uma incompatibilidade de fundo entre os argumentos do multiculturalismo e de um de seus adversários. MacIntyre nos guiou com três pontos básicos para problematizar nossos debates morais, sugerindo radicalmente que não haveria solução alguma devido à variabilidade de tradições de pesquisa sustentando as teses em confronto. Ao levarmos a hipótese de MacIntyre para o feixe de argumentos no multiculturalismo, mostramos que (a), (b) e (c) estabelecem um consórcio que liga o sentido de um conceito ao contexto histórico do seu surgimento. Isso denota a necessidade da existência de um elo entre uma elocução moral e a circunstância de sua emissão. Todavia, este é exatamente o elemento descartado dentro do que é exigido, em termos argumentativos, nas nossas atuais contendas morais. Portanto, sem querer comprometer os méritos da tradição política liberal (os quais são muitos e importantes para o próprio surgimento do multiculturalismo), chegamos à conclusão de que uma visão comunitarista sobre as questões morais fornece algumas chaves interpretativas que nos permitem vislumbrar saídas para as críticas que tentam minar a fertilidade de nossas atuais discussões morais e políticas.

\footnotetext{
13 Neste trabalho, nos foi impossível entrar em questões que especificassem e detalhassem as transformações modernas, como a revolução industrial, as reformas religiosas e outros fatores bastante amplos que contribuíram historicamente para a noção de indivíduo surgida no Ocidente. Além do espaço inicialmente planejado para o presente trabalho, tal debilidade se deve ao fato de termos seguido os textos de Charles Taylor, nos desviando, em parte, das transformações materiais.
} 


\section{Referências}

ANSCOMBE, G.E.M. Modern Moral Philosophy. Philosophy 33 No. 124 January 1958.

BEZERRA, V. A. Valores e incomensurabilidade: meditações kuhnianas em chave estruturalista e laudaniana. Scientiae studia. vol.10 no.3 São Paulo 2012.

BARRY, B. Culture and Equality: An Egalitarian Critique of Multiculturalism, Cambridge, MA: Harvard, 2001.

CALANDÍN, J. G. Modernidad hermenéutica en Charles Taylor. Quaderns de filosofia i ciència, 40, 2010, p. $105-114$.

CRISP, R. Reasons and the Good, Oxford University Press, 2006.

KYMLICKA, W. Multicultural Citizenship: A Liberal Theory of Minority Rights, Oxford: Oxford University Press, 1995.

IVISON, D. "Historical Injustice," in The Oxford Handbook of Political Theory, J. Dryzek, B. Honig, and A. Phillips (eds.), Oxford: Oxford University Press, 2006, p. $507-25$.

LOIS, C. C. (org). Justiça e Democracia: entre o Universalismo e o Comunitarismo, São Paulo, Landy Editora, 2005.

MACINTYRE, A. Depois da Virtude. São Paulo: EDUSC, 2001.

SATTLER, J. "Alternativas à "Filosofia Moral Moderna": Considerações Wittgensteinianas, Estoicas e Literárias". In: Ética, linguagem e antropologia: perspectivas modernas e contemporâneas / org. Juliano Santos do Carmo, Robinson dos Santos. - Porto Alegre: EDIPUCRS 2012, p.103 - 144.

SEMPRINI, A. Multiculturalismo. Bauru: EDUSC, 1999.

SONG, S. Multiculturalism. In E. N. Zalta (Ed.), The Stanford Encyclopedia of Philosophy, 2016. Disponível em: http://plato.stanford.edu/entries/multiculturalism/.

TAYLOR, C. Multiculturalismo: examinado a política de reconhecimento. Lisboa: Instituto Piaget, 1994.

. Hegel e a sociedade moderna. Ed. Loyola, São Paulo, 2005. 2005.

As fontes do self: a construção da identidade moderna. São Paulo, SP: Loyola,

TUGENDHAT, E. Lições sobre ética. Petrópolis, RJ: Vozes, 1996.

Autor(a) para correspondência: Willian Martini, Universidade Federal de Santa Catarina, Centro de Filosofia e Ciências Humanas, Trindade, CEP 88040-970, Florianópolis - SC, Brasil. willianmartini@hotmail.com 